\title{
Evolution of An Integrated, Project-BAsed Logistics ENGINEERING CURRICULUM
}

\author{
Zbigniew J. Pasek ${ }^{1}$, Pawet Pawlewski ${ }^{2}$ \\ ${ }^{1}$ University of Windsor, ${ }^{2}$ Poznań University of Technology \\ zjpasek@uwindsor.ca,pawel.pawlewski@put.poznan.pl
}

\begin{abstract}
This paper describes the evolution of content and teaching practices of an innovative undergraduate curriculum developed for a new Logistics Engineering degree program. Originally proposed and implemented in 2010, the bi-level curriculum follows European directives and complies with the Bologna Process. Over the years the content and teaching practices were continuously reviewed and modified to stay in sync with teaching practices of design and entrepreneurship, progress simulation technologies, and student responses.

Since the initial introduction of the curriculum many advances in various relevant areas have taken place and consequently the content of the curriculum had to be updated. For example, Lean Startup Method using Business Model Canvas has replaced business plans in teaching entrepreneurship. Similarly, as general softwarebased simulation tools have grown in complexity, teaching them requires more time and becomes time-impractical. A simpler approach based on limited-instruction tools tailored for product assembly, but built on these general simulation platforms, offers a more effective practical solution.
\end{abstract}

Keywords: Lean Start-up, entrepreneurship, design thinking, process modeling and simulation, logistics, engineering education.

\section{INTRODUCTION}

The core of the program is based on a sequence of four major courses, which focus on the Product Development, Process Analysis and Optimization, Logistic Processes and Service Engineering. Each course is built around a practical team project. With the project effort as the background, the courses introduce students to key issues in global engineering competence, including collaboration and teamwork, work organization and management, engineering ethics, cross-cultural communication, critical thinking and problem solving, and integration strategies for design, manufacturing and marketing. Projects also introduce entrepreneurial components, as the teams have to develop their concepts in the context of a start-up company. The unique feature of the 4-course project sequence is that the outcomes of each project from a preceding stage serve as an input in the following stage, building not only students' competences but also assuring learning continuity and enforcement $[14,12]$.

The first course in the series, introduces 2nd year students to basic concepts of consumer product development. It covers the principles of design and innovation process, and also explains essential design tools, such as Design Thinking, QFD and Pugh Matrices. It also reviews key manufacturing methods and systems. Students work in small teams to develop their own product ideas from initial concepts to a business plan for a start-up. The course is offered in English.

The second course, offered to 3rd year students, introduces fundamental concepts related to industrial process analysis, simulation, and improvement. Students learn necessary data collection and analysis techniques (such as, for example, Value Stream Mapping) and also the basics of process simulation using a commercial software package. Student teams work with industrial sponsors and develop competing innovative ideas for process transformation and improvement.

The third course is offered to 4th year students in the first year of their master's program. It covers process management and optimization, initially focusing on factory-level processes, and the more broadly on Supply Chain. Tools for assessment of process performance, lifecycle analysis and management are discussed. The student group projects are carried out in an industrial setting, addressing real-life assignments.

The final course, integrating knowledge acquired by the students in the preceding sequence, is focused on the issues of service engineering. It covers such topics as, for example, service design, customer journey mapping, service and prototyping, digitalization issues, service operations and business model innovations. It also addresses issues of strategy and performance evaluation.

Over past 10 years each of the first three courses had an annual cohort size of 90-130 students, totaling over 1,000 students. In each of the courses the students, divided into teams have worked on 9 to 12 projects. These projects were growing in complexity and depth, as students progressed through the curriculum. 


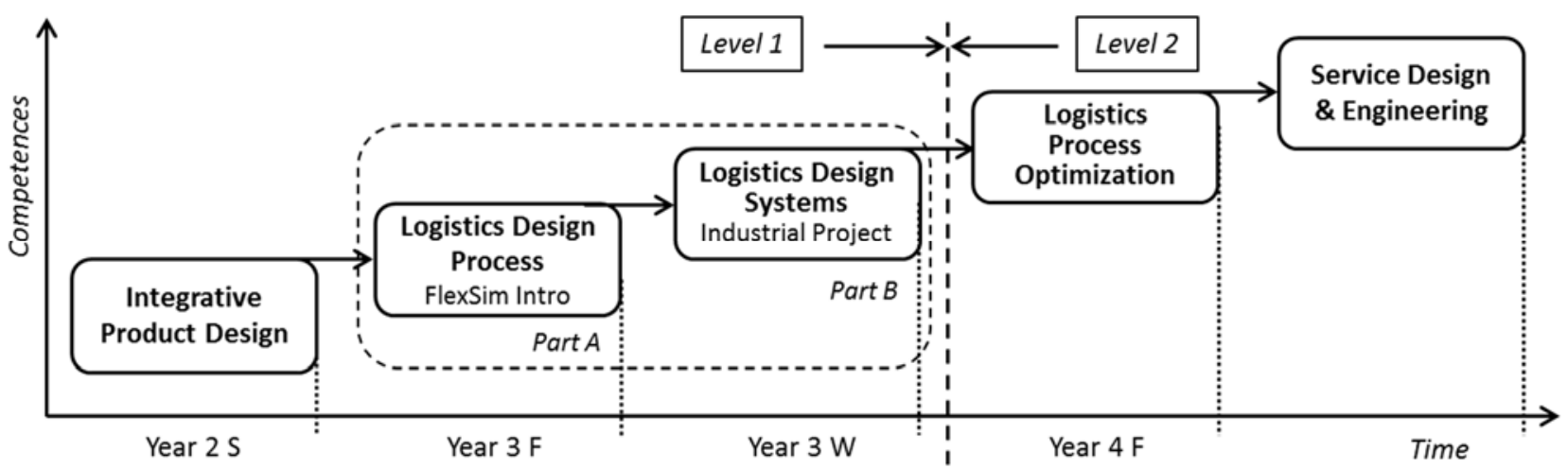

Figure 1: Original course sequence in the curriculum.

Table 1 provides a summary of the hourly teaching efforts involved in each of the courses included in the curriculum.

Table 1: Teaching hours across the curriculum

\begin{tabular}{|c|c|c|c|}
\hline Course & Lectures & Tuts/Labs & Project \\
\hline IPD & 15 & 15 & $(10)$ \\
\hline LPD-1 & 30 & 15 & - \\
\hline LPD-2 & - & - & 30 \\
\hline LSD & 15 & 15 & 15 \\
\hline SDE & 15 & 15 & $(10)$ \\
\hline
\end{tabular}

(\#) represent informally implied student effort in projects.

\section{EXTERNAL DISRUPTIVE TRENDS}

Since the initial introduction of the curriculum many advances in various relevant areas have taken place and consequently the content of the curriculum had to be updated. On the other hand, some of the initial ideas either did not work out in practice or turned out to be too cumbersome in practical implementation.

\subsection{Lean Startup Approach}

Lean Startup approach, initiated and popularized by [2], is a methodology used by early stage ventures to shorten the product development stage and introduce the product in the market in much faster way. Instead of devoting time and money in developing final products in the beginning, Lean Startup methodology proposes to integrate prospective customers' feedback during the product development stages through a string of rough product prototypes, delivering only basic functionality. In this way, entrepreneurs minimize waste of time and money in developing a product which may have no value to customers.

As prior research suggests "learning by doing" is more effective than traditional business plan development teaching [7]. Consequently, educators are using different methodologies to deliver hands-on experience for students. Lean start-up is a fairly new an experiential methodology introduced to teach entrepreneurship over the past 10 years.
It has been successful in replacing the popular in the past business plan as a path to successful entrepreneurial product development.

Independently from Blank's initiatives at Stanford's Design School, a number of other useful tools have been developed over the recent years to facilitate the Lean Startup Process, most notable the Business Model Canvas and the Value Proposition Canvas [10]. These tools have helped to formalize and standardize the approach, making it a prevalent and popular not only among professional entrepreneurs, but also in teaching entrepreneurship in many post-secondary institutions.

\subsection{Design Thinking}

While traditional engineering design process is fairly well established, it work best for well-structured problems that can be solved in a systematic way using primarily analytical methods. Design Thinking (DT) is a problem solving methodology especially well-suited for investigating ill-defined problems that is human-centered, possibility-focused, and hypothesis-driven. It is a style of thinking that combines empathy for the users and immersion in the context of a problem, creativity in the generation of insights and solutions, and a data-based experimental approach to assessing the quality of solutions [9].

Over past two decades Design Thinking has been popularized and used broadly as a preferred design approach $[17,19]$ that can be applied successfully to a variety of situations, such as, for example, technical, social, environmental, etc.

Within the context of DT framework, and more specifically Human Centered Design (HCD), a variant of DT, students encounter problematic situations that expose conflicting, paradoxical demands (these are often referred to as wicked problems). For engineering students such exposure is beneficial as it allows them to appreciate and expand their design approach by embedding empathy and elevating understanding of human conditions they face, even though it may cause significant axiological stress [5]. 


\subsection{Simulation Software}

For a number of decades now, broad swaths of industries are set on a digital transformation trajectory. IN particular, automotive industries, leveraging advent of CAx methods and physics-based models, and the need to reduce their operating costs, have embarked on adoption of digital solutions whenever possible, starting with digital product modeling and testing, through digital manufacturing and supply chain simulations. As a result, modeling and simulation software in this domain is now routinely used.

The simulation technologies are also evolving, driven primarily by ability to create and use more complex models that include increasing number of controllable objects, the need to handle large amounts of simulation data, and also by visualization tools available (e.g., 2-, 3-D or VR).

Initially, when the curriculum development started, a simulation software package from Lanner, called Witness, was adopted, as it was already in use at the university. However, within two teaching cycles it turned out that it did not have sufficient simulation capabilities, in particular in visualization. Its technical support was also lacking. This situation resulted in initial software review of available competing packages, and selection of FlexSim software, which already was offering, among other improvements, the following features $[1,4]$ :

1. Ease of use in a real time (with drag $\&$ drop),

2. Built-in 3D modeling,

3. Direct upload of CAD files directly into a model,

4. Extensive library of pre-built objects (e.g., vehicles, cranes, robots, elevators, conveyors, etc.).

5. Built-in experimentation tool and link to optimizer.

6. Task-executer and task-sequence technologies.

\subsection{Internet of Things and Industry 4.0}

In 2013 Working Group on Industry 4.0 presented design guidelines for the current $\left(4^{\text {th }}\right.$ generation $)$ automation systems and data exchange in manufacturing technologies; these include cyber-physical system, the Internet of Things, cloud computing and cognitive computing [18]. Industry 4.0 advocates aggressive push for development of "smart factories," where complex physical systems work and are being monitored in tandem with their virtual, digital copies, and achieve optimized operations by use self-optimization, self-configuration, self-diagnosis, cognition and intelligent support of workers in their increasingly complex work. The key principles of Industry 4.0 are as follows:

- Digital and flexible factory with continuous and immediate communication capabilities among its element, integrated into production lines and supply chains.

- Extensive use of simulation tools and data processing to collect and analyze data from production systems.
- Economical use of energy and resources by factory through coordinated assessment of needs and availability.

The Industry 4.0 concept not only relies heavily on a variety of modeling and simulation tools, but also defines a set of competences required of employees, defined no longer as "workers," but rather as "engineers," given that their job is now to integrate, manage, control work of machines and analyze large amounts of data. Thus one of the imperatives for successful implementation of Industry 4.0 is to find employees with appropriate competences.

Competences of this new class of workers include: knowledge, skills (soft skills and technical skills) and attitude, reflected in actions.

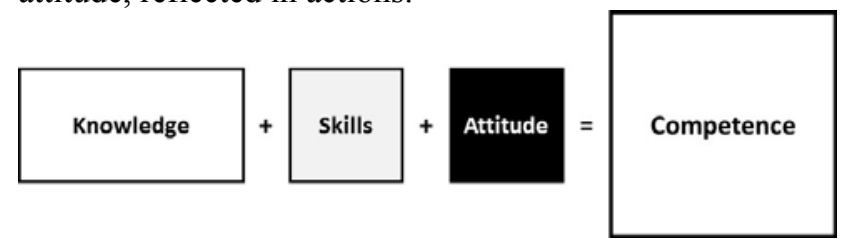

Figure 2: Competence structure.

The knowledge component may be achieved in either formal or informal way, to include various categories of knowledge: know - what, know - why, know - how and know - who. The skills can be built by experience over time and are based on practical abilities. Finally, the attitude expresses willingness and readiness for using the knowledge and skills in action. Recent studies by Fraunhofer Institute [8] have identified key categories of employee competences that fit the needs of Industry 4.0 (see Fig. 3).

\begin{tabular}{|c|c|c|}
\hline Technology & Process & Infrastructure/Org. \\
\hline $\begin{array}{l}\text { L1: Interdisciplinary } \\
\text { thinking \& action } \\
\text { L2: Problem solving \& } \\
\text { optimization } \\
\text { L3: Scope of work, } \\
\text { complex control } \\
\text { L4: Ability to } \\
\text { cooperate/interact } \\
\text { with machines }\end{array}$ & $\begin{array}{l}\text { L5: Process's } \\
\text { knowledge \& } \\
\text { growth } \\
\text { L6: Participation in } \\
\text { innovation } \\
\text { processes } \\
\text { L7: Ability to work with } \\
\text { and coordinate } \\
\text { processes }\end{array}$ & 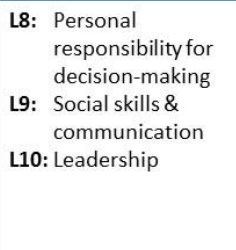 \\
\hline
\end{tabular}

Figure 3: Employee competencies for Industry 4.0 [8]

Development and industry-wide adoption of Industry 4.0 concepts, even though its goals are still in the future, allowed to put the purpose and learning objectives of the discussed curriculum into much sharper focus and alignment.

\section{IMPLICATIONS FOR COURSE CONTENTS}

All trends listed in section 2 have a significant impact on the engineering practices, both in industry, academia and engineering education. 


\subsection{Integrative Product Design}

The introduction of the Lean Startup approach (jointly with Design Thinking) and all associated support tools has generally solidified structure of the course and improved flow and alignment of student activities.

For example, key document driving the product development process in a startup enterprise is the Business Model Canvas (BMC), which emerged through Lean Startup efforts. While in itself it has not been the easiest to explain and clarify relationships between 9 fields it consists of, that difficulty has been recognized by original creators and supporting tool, called Value Proposition Canvas (VPC), has been developed and made available to the public. That helped to break the BMC creation process into two steps, the first of which focuses on identifying customer problem to be solved and charting the possible path to problem solution. The results from the VPC can be immediately ported to $\mathrm{BMC}$ and the development can proceed further.

Another important need in BMC creation are the (potential) customer interviews. These are usually quite challenging for the engineering students, who are not only forced to articulate their ideas in layman's terms, but also have to talk to strangers. Is such tasks are presented in the form of baby steps (e.g., by development of detailed interview scenarios and forms), they do not seem to students as unsurmountable obstacles.

Similarly, creation of hands-on Design Thinking exercises, where students work in pairs interviewing each other, initially as designers and then are being interviewed as being customers for the said design, then they understand better those differing perspectives and can almost literally :walk in customer' shoes."

Outcome of the course is in the form of a group report containing conceptual design of the product, including the Bill of Materials (BOM), the description of manufacturing processes necessary to make it, and initial layout of the process flows (e.g., main process and supporting processes). That information set is used as an input to the second course in the sequence (Logistics Process Design).

It is also worth mentioning that this course, which is offered in a sprint form over 8 days, has been modeled after the regular full engineering course developed by the first author at the University of Windsor (36 hours of lectures and 24 hours of tutorials) [11].

\subsection{Logistics Process Design - FlexSim Intro}

As it was already mentioned in section 2.3 , one important change took place relatively early after the curriculum was launched. It involved switch of the simulation platform, from Witness to FlexSim package, and it was primarily driven by the need to provide 3-D visualization. Flexsim platform is a versatile and functionally capable software package, yet easy to use, tool for building three-dimensional computer models of operational systems and analyzing their performance. Simulation can be performed at significantly lower cost than experimenting with a real system. It also helps users to understand, visualize, and validate the operation of a pro-posed system before it is implemented. Since 2015 FlexSim has had the ability to create custom objects that has been able to easily incorporate logic needed to model complex business processes.

More recently, another modification took place and is still being fully implemented. Over the years, FlexSim, similarly to other simulation platform had grown considerably, and its library of functions and commands became extensive. The company that offers it suggest an introductory training in a form of 7-day hands-on workshop: that's a total of 56 hours, which is almost twice the amount of time allocated to lectures in the course (!). So it obviously is not possible to prepare students adequately to develop models their projects, verify and debug them, and then run a gamut of simulation scenarios to be interpreted. AS the system functionality grew, minimally sufficient preparedness of the students could only be reached in the final weeks of the course, and that did not leave enough time for significant work. Another solution was required.

On the one hand FlexSim becomes more complex software too, requiring expert-level skills from the users. On the other hand, over many project implementations it became apparent that routinely new simulation projects tend to start unnecessarily from scratch, while many repetitive activities can be effectively automated. The users, whether they are students or industrial logistics experts, do not have sufficient programming skills (and generally are not interested in acquiring them) to properly apply such an omnibus software, as they prefer to focus on solving logistics issues, rather than building models and using them for simulation, which is time- and effort consuming.

To address these needs, a simulation software named LogABS, relying on the internal FlexSim's graphic engine, was developed. It is a dedicated 3D application, narrowly focused on design and re-design of factory/process layouts. The key driver for its development was user costs reduction: time-consuming model building, batch data preparation, and solution variants testing can be substantially reduced. It has a built-in automated valueadded (VA) analysis and Lean analysis, operator workloads, distances traveled, inventory levels (for selected sites), workcycles of operators, robots, forklifts and AGVs, logistic trains. Using LogABS students (engineers) use the same language as they use in their daily work.

Since the primary focus of the simulations created by students in the course are related to final assembly and intralogistics operations (e.g., internal transport with factory), it turned out that it was possible to define a reduced set of 61 instructions, which sufficiently cover 
these operations $[13,15,16]$. As a result, for students to create the working models it was sufficient to study and understand the reduced instruction set, without going into the details of the whole simulation platform. Pedagogical support for that solution is still being developed, but the first run of the course inn this format while still had some glitches was otherwise rather successful. The important advantage is that the LogABS instructions set is also easily understandable by operators and engineers in the industry, as it pertains to what they do daily (and not the inner details of the software).

\subsection{Logistics Systems Design - Project}

The culminating projects in the 3rd course were carried out in collaboration with local companies. Overall, 93 such projects were successfully completed in the period of interest. They were usually falling into one of three categories of simulation model building:

- Technology-oriented (25\% of projects), e.g. designing storage technologies for a central warehouse of a company.

- Process-oriented (43\%), e.g., picking process simulation in an automated, palletized warehouse.

- Infrastructure/organization oriented (33\%), e.g., concept development of an internal transport system in the production facility and optimization of the use of transhipment ramps.

It is also worth mentioning that Logistics Engineering program holds an Annual Gala where the results of most recent student project are presented. The event is well attended not only by students, who co-organize it, but also invited industry representatives, and not only from companies sponsoring projects, but also those interested in developing relationship with university and considering future project engagements.

\subsection{Logistics Systems Optimization}

The FlexSim software contains built in optimization modules, Experimenter tool and OptQuest. The first one allows to run pre-defined scenarios through the working model to perform in-depth study. Then the most promising scenario can further improved by running it through OptQuest module. More importantly, these operations can also be conducted using the models build using LogABS, and allow students to focus on better understanding how their models work and how to improve their performance.

\subsection{Service Design \& Engineering}

This course has been so far offered only once and can be considered under development. However, the current content includes both Design Thinking, as well as Lean Startup approach, both adjusted to be applied to services. Use of simulation is being considered, although it would require development of corresponding limited instruction set for services.

\section{SUMMARY}

The original aim of the Logistics curriculum was rather ambitious, as it aimed at preparing them as new generation of logistics engineers, expert not only in theory abut also well versed in advanced simulation technologies. So far the popularity and ranking of the program placed it in the top 3 in Poland, thus it can be considered successful.

\section{References}

[1] Beaverstock, M., Greenwood, A., Nordgren, W.: Applied Simulation. Modeling and Analy-sis using Flexsim, Flexsim Software Products, Inc., Canyon Park Technology Center, Orem, USA, (2017)

[2] Blank, S. and Dorf, B. (2012). The Start-up Owner's Manual. Pescadero, K \& S Ranch

[3] Da Silva, G., Gomes Costa, H., and De Barros, M. (2015). Entrepreneurship in Engineering Education: A Literature Review, International Journal of Engineering Education, 31 (6A), 1701-1710.

[4] Dias, L. et al, (2016), Discrete Simulation Software Ranking - A Top List of Worldwide Most Popular and Used Tools, Winter Simulation Conference

[5] Dym, C. L., Agogino, A. M., Eris, O., Frey, D., Leifer, J. L. (2013). Engineering Design Thinking, Teaching, and Learning. Journal of Engineering Education, 94 (1), 103120.

[6] FlexSim website: https://www.flexsim.com (FlexSim Software Products)

[7] Honig, B. (2004). Entrepreneurship Education: Toward a Model of Contingency-Based Business Planning. Academy of Management Learning \& Education, 3(3), 258-273.

[8] Kagermann H., Helbig J., Hellinger A., Wahlster W., 2016, Acatech, Fraunhofer Insti-tut für Materialfluss und Logistik, equeo GmbH: Kompetenzentwicklungsstudie Indus-trie 4.0. Report.

[9] Liedtka, J. (2017) Evaluating the Impact of Design Thinking in Action. Academy of Management Proceedings. Vol. 2017. No. 1. Academy of Management, 2017.

[10] Osterwalder, A. and Pigneur, Y. (2010). Business Model Generation, Hoboken, NJ, Wiley.

[11] Pasek, Z. J., Schlosser, F. (2014). Modern Engineering Sandwich: Management, Globalization and Entrepreneurship on Top of Product Development, 2014 ASEE Annual Conference, Indianapolis, June 15-18, 2014.

[12] Pawlewski P., Pasek, Z. J. (2012) Integrating student projects through the use of simulation tools across logistics engineering curriculum. 2012 ASEE Annual Conference, San Antonio, Texas 
[13] Pawlewski P. (2018) „Methodology For layout and Intralogistics Redesign Using Simulation" in Proceedings of the 2018 Winter Simulation Conference M. Rabe, A.A. Juan, N. Mustafee, A. Skoogh, S. Jain, and B. Johansson, eds.

[14] Pawlewski P., Pasek Z. J. (2011) Logistics engineering curriculum integrated through student projects, Research in Logistics \& Production, Vol. 1, No. 1, Publishing House of Poznan University of Technology, pp.27-44.

[15] Pawlewski, P. (2018) "Practical application of a multimodal approach in simulation modeling of production and assembly systems", Distributed Computing and Artificial Intelligence, 15th Int. Conference, (eds.) Fernando De la Prieta et al. in: Advances in Intelligent systems and Computing, Springer 2018

[16] Pawlewski, P. (2018) "Script language to describe agent's behaviors", Highlights of Practical Applications of Complex
Multi-Agent Systems - Int. Workshops of PAAMS 2018 (eds.) Javier Bajo et al. Springer

[17] Rother D.S. , Açar A.E. (2011) Design Thinking in Engineering Education and its Adoption in Technologydriven Startups. In: Seliger G., Khraisheh M., Jawahir I. (eds) Advances in Sustainable Manufacturing. Springer.

[18] Schwab K. (2017) The Fourth Industrial Revolution. Penguin UK.

[19] Zancul, E. D., Durao, L. F., Lopes, R. D., Nakano, D., Blikstein, P., Majzoub, G., \& Dalmon, D. (2017), An Empirical Study on Design-Based vs. Traditional Approaches in Capstone Courses in Engineering Education. International Journal of Engineering Education, 1543-1560. 